\title{
Study on the relation between damage and permeability of sandstone at depth under cyclic loading
}

\author{
Yang Zhao ${ }^{1,2} \cdot$ Hongwei Zhou ${ }^{3,4} \cdot$ Jiangcheng Zhong ${ }^{1} \cdot$ Di Liu $^{5}$
}

Received: 24 August 2019/Revised: 5 September 2019/Accepted: 14 October 2019/Published online: 12 November 2019

(C) The Author(s) 2019

\begin{abstract}
The damage and permeability evolution of rock under stress is of great significance to engineering safety. In this paper, the evolution law of rock damage and permeability is studied by means of acoustic emission (AE) seepage experiment on deep roof sandstone with cyclic loading. Characterization of damage uses the changes in acoustic emission fractal characteristics and compression parameter which based on elastic modulus. The experimental results show that the $\mathrm{AE}$ events has fractal characteristic, in which the $\mathrm{AE} b$-value and correlation dimension can represent the damage of rock. When the fractal characteristic value of AE increases, it indicates that the rock is in the compaction stage and the damage is not obvious. When the fractal characteristic value of AE drops, it indicates that the rock was damaged, and the permeability increase. Under the cyclic load increasing step by step, the elastic modulus first increases and then decrease. Introducing compression parameter $C$ to characterize the state of compaction and damage, it is obtained that the rock damage state and hydrostatic permeability show a power law function relationship with porosity and have the same monotonicity. When compression parameter is less than zero, the evolution law of permeability and damage can be described by functional relationship between hydrostatic permeability $K$ and compression parameter $C$.
\end{abstract}

Hongwei Zhou

zhw@cumtb.edu.cn

Yang Zhao

zhao_no1@126.com

Jiangcheng Zhong

zhongjc1988@126.com

Di Liu

diligentkids@sina.com

1 School of Mechanics and Civil Engineering, China University of Mining and Technology, Beijing 100083, People's Republic of China

2 Mine Safety Technology Branch of China Coal Research Institute, Beijing 100013, People's Republic of China

3 School of Energy and Mining Engineering, China University of Mining and Technology, Beijing 100083, People's Republic of China

4 State Key Laboratory of Coal Resources and Safe Mining, China University of Mining and Technology, Beijing 100083, People's Republic of China

5 School of Aerospace Engineering, Tsinghua University, Beijing 100084, People's Republic of China
Keywords Deep roof sandstone - Cyclic loading · Acoustic emission · Permeability

\section{Introduction}

The damage and permeability evolution law of deep sandstone is studied experimentally in this paper. Deep rock under high geostress conditions has different rock structure, physical mechanics and seepage properties from shallow rock. The damage and permeability property of deep coal seam working face roof sandstone under the effect of stress is of great significance (Zhou et al. 2005). The definition of rock damage is mainly based on the triaxial experimental measurement of basic mechanical parameters include stress-strain, elastic modulus and acoustic emission (AE) fractal characteristic value (Zhang et al. 2015).

Rocks produce significant $\mathrm{AE}$ signals under compressive stress. The energy and position information of the AE can reflect the damage of the rock. For rock materials, the $\mathrm{AE}$ has good fractal characteristics, and the $\mathrm{AE} b$-value and $\mathrm{AE}$ 
correlation dimension are closely related to rock damage. The AE characteristics of rocks under different stresses are different. In general triaxial experiments, the AE signals often have phase characteristics. The cyclic loading experiments can better obtain the $\mathrm{AE}$ characteristics of rocks under different stress states.

The deformation damage characteristics of rock under compressive stress can be divided into compaction stage, elastic stage, fracture yield stage, failure stage and strain softening stage after failure (Eberhardt et al. 1998; Lajtai and Lajtai 1974). The strain damage characteristics at various stages can be characterized by the elastic modulus that is one of the main mechanical properties of rock, which can be defined as the ratio of deviatoric stress increment to axial strain increment in a broad sense. Stress-strain curve is usually obtained by triaxial compression experiments. The ratio of the stress increment to the strain increment of a rock under increasing stress is gradually changed depending on the property of the rock. In general, the stress-strain curve of rocks shows three types: plastic soft rock with low strength and strong plastic characteristics, shallow rock with elastic characteristics and obvious yield stage, and deep rock with high strength and strong brittle characteristics (Cai et al. 2002; Fang and Harrison 2002; Li and Li 2017; Zhang and Zhao 2013; Zhou et al. 2010). That is, different types of rocks have different elastic modulus properties under different stress conditions. Therefore, the cyclic loading experiment can obtain the mechanical properties of various stress stages of rock more accurately (Elliott and Brown 1986; Martin and Chandler 1994; Zhou et al. 2019). This paper defines the rock damage evolution under cyclic loading reference to the fractal characteristics of $\mathrm{AE}$ values and the elastic modulus of the rock. Then, the evolution of rock permeability with damage is studied based on the AE seepage experiment under triaxial stress condition.

\section{Experiment design}

\subsection{Preparation of specimens}

The sandstones used in the experiment are taken from the $1050 \mathrm{~m}$ deep face roof of Pingdingshan Coal Mine Group 12. The ground stress of the rock is $42.07 \mathrm{MPa}$ at the maximum, $21.79 \mathrm{MPa}$ at the minimum, and $25.63 \mathrm{MPa}$ at the vertical direction. The buried depth of rock samples and the ground stress condition in this paper belongs to the deep range (Zhou et al. 2005). The recovered roof sandstone is drilled and processed into cylindrical rock samples with a diameter of $50 \mathrm{~mm}$ and a height of $100 \mathrm{~mm}$.

Compared with shallow rock mass, roof sandstones taken in this paper have a greater compressive strength and elastic modulus. The higher clay content of rock samples is about $40 \mathrm{GPa}$, while the lower clay content is about $60 \mathrm{GPa}$. The friction angle is $52.87^{\circ}$, cohesion is 23.59 MPa. The porosity of rock sample is less than $1 \%$, the density is about $2.70-3.22 \mathrm{~g} / \mathrm{cm}^{3}$, and the permeability is on the order of micro-Darcy $(\mathrm{mD})$. According to the property measurement results, the selected deep face roof sandstone is a dense rock mass with high density, high strength, low porosity and ultra-low permeability. Conventional triaxial test is conducted on rock sample $3-7$ as a reference, and $\mathrm{AE}$ permeability test is conducted on rock samples 2-1, 2-4, 3-6 for cyclic loading.

\subsection{Experiment method}

In order to obtain the fractal characteristics of rock $\mathrm{AE}$ and the evolution law of permeability, the experimental system MTS815 of Sichuan university, as shown in Fig. 1, is used to conduct conventional triaxial compression and triaxial compression cyclic loading AE permeability experiments on the roof sandstone of deep working face. The confining pressure of the conventional triaxial experiment is $25 \mathrm{MPa}$, and the three confining pressure conditions selected in the cyclic loading experiments are 5, 15 and $25 \mathrm{MPa}$, respectively. The loading and unloading process is controlled by displacement. The loading rate is $0.06 \mathrm{~mm} / \mathrm{min}$ and the unloading rate is $0.1 \mathrm{~mm} / \mathrm{min}$. The $\mathrm{AE}$ measurement is synchronously carried out with loading and unloading in the whole course, and the stress path of cyclic loading is shown in Table 1. Each cyclic loading starts from the hydrostatic pressure state, and is loaded to the peak of the current partial stress, and then unloaded to the hydrostatic pressure state.

\subsection{Permeability measurement}

The experimental measurements of permeability are divided into two categories (Brace et al. 1968; Wang et al. 2015a, b), the steady state method and transient method. Due to the sample used in this paper is compact and low permeability material that is suitable for transient method

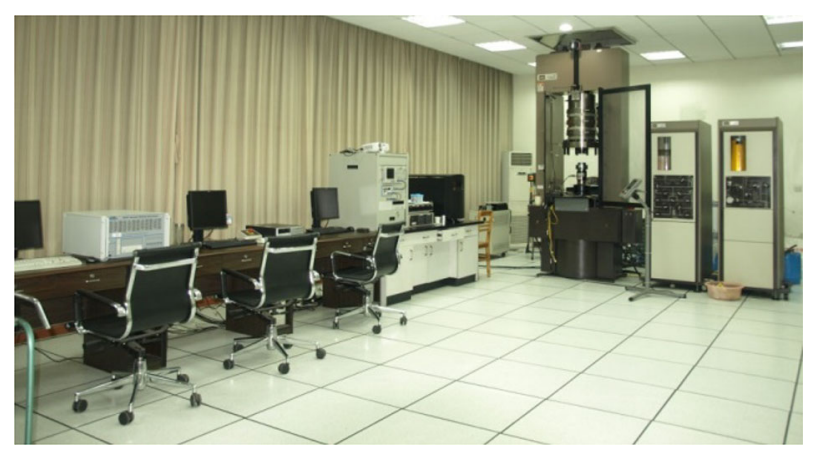

Fig. 1 MTS 815 flex test GT rock mechanics testing system 
Table 1 Deviatoric stress peak corresponding to each cycle of cyclic loading test

\begin{tabular}{lllllllllll}
\hline Specimen & Confining pressure (MPa) & \multicolumn{9}{l}{ Deviatoric stress peak for each cycle (MPa) } \\
\cline { 3 - 11 } & & 1 & 2 & 3 & 4 & 5 & 6 & 7 & 8 \\
\hline $2-1$ & 5 & 50.972 & 76.898 & 102.631 & 132.710 & 163.022 & 175.895 & 203.636 & 224.456 & 146.504 \\
$2-4$ & 15 & 80.305 & 122.675 & 163.143 & 213.961 & 259.498 & 286.989 & 101.124 & 100.680 & 97.334 \\
$3-6$ & 25 & 78.802 & 112.961 & 149.597 & 173.593 & 197.287 & 217.185 & 214.632 & 108.035 \\
\hline
\end{tabular}

(Li et al. 2001; Sun et al. 2013; Zhang et al. 2000a, b). Permeability is measured at hydrostatic pressure and peak stress for each cycle. Water is used as the infiltrating medium in the infiltration experiment, and the osmotic pressure difference is designed to be $3 \mathrm{MPa}$ based on the hydraulic pressure conditions of the working face. In the process of cyclic loading, when the axial pressure and confining pressure reach the same state of hydrostatic pressure and the stress reach the peak of the secondary cycle, the dynamic shaft displacement of experimental machine is maintained unchanged for permeability measurement.

Transient method is employed to calculate the permeability, which could be used for the measurement of permeability of low-permeability rock. The schematic diagram of its testing principle is shown in Fig. 2: during the permeability test, the fluid pressure of closed container at the high-pressure side of rock sample suddenly increased, and the fluid pressure is transferred from the high-pressure side to the container at the low-pressure side through rock sample. In the process of seepage, the pressure of container at the high-pressure side decrease gradually while the pressure of container at the low-pressure side increase gradually, and the pressure difference between the two decrease gradually. The permeability is calculated by

$k=\mu \beta V\left[\ln \left(\frac{\Delta P_{i}}{\Delta P_{f}}\right) /\left(2 \Delta t \frac{A_{s}}{L_{s}}\right)\right]$

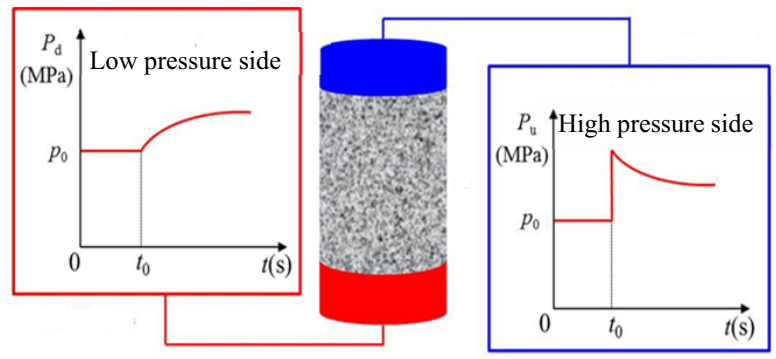

Fig. 2 Schematic diagram of transient pulse technique (Escoffier et al. 2005) where $k$ is permeability $\left(\mathrm{m}^{2}\right), \mu$ is the viscous coefficient of fluid (for the water at about $20^{\circ} \mathrm{C}$ water, it is $1.011 \times 10^{-3}$ $\mathrm{Pa} \cdot \mathrm{s}), \beta$ is the fluid compressibility $\left(4.53 \times 10^{-10} \mathrm{~Pa}^{-1}\right)$, $V$ is the reference volume of pressure stability container $\left(\mathrm{m}^{3}\right), \Delta P_{i}, \Delta P_{f}$ are the differential pressure (MPa) between top and bottom container at the initial time $t_{\mathrm{i}}$ and the final time $t_{\mathrm{f}}, \Delta t$ is the permeability test duration (s), namely, $\Delta t=t_{\mathrm{f}}-t_{\mathrm{i}}, L_{\mathrm{s}}$ is the tested cylindrical sample length (m), $A_{\mathrm{s}}$ is the cross-sectional area $\left(\mathrm{m}^{2}\right)$ of tested cylindrical sample.

The permeability results of rock samples obtained, as shown in Table 2, show that the variation of rock permeability under the cyclic stress has strong regularity. The permeability reduces as the cyclic stress increases when the stress level is low, then increases slightly when the stress level reaches to yield and failure stage, sudden increases when rock sample is at failure and once more reduces at post-peak stage. Comparing the hydrostatic pressure and the peak stress permeability, in the process of cyclic loading before failure, the permeability of rock samples under hydrostatic pressure is greater than that at the peak of the cycle, and the initial permeability of rock samples under the first hydrostatic pressure is relatively large. It is shown that stress plays a major compacting role in the rock sample before rock failure, which causes the internal micro-cracks and pore sizes of the rock to decrease or even close, thus leading to a substantial decrease in the overall permeability of rock sample. Stress plays a major fracturing role after rock sample reaches yield and failure stage, while the primary fractures within the rock sample expand and new fractures are generated due to the large stress, which lead to the increase of permeability. Stress after the rock sample failure decreases to nearly half of the strength of rock, in this stage, it mainly plays compacting role so that the permeability will decrease compared with that when damaged.

\subsection{Acoustic emission measurement}

The acquisition of $\mathrm{AE}$ is conducted simultaneously with triaxial experiment. After the $\mathrm{AE}$ probe is coated with vaseline, pressure is applied through the clamping ring to make it in close contact with the outer wall of the triaxial 
Table 2 Permeability measurement results

\begin{tabular}{|c|c|c|c|c|c|c|c|}
\hline \multicolumn{2}{|l|}{$3-7$} & \multicolumn{2}{|l|}{$2-1$} & \multicolumn{2}{|l|}{$2-4$} & \multicolumn{2}{|l|}{$3-6$} \\
\hline $\begin{array}{l}\text { Deviatoric stress } \\
(\mathrm{MPa})\end{array}$ & $\begin{array}{l}\text { Permeability } \\
(\mu \mathrm{D})\end{array}$ & $\begin{array}{l}\text { Deviatoric stress } \\
(\mathrm{MPa})\end{array}$ & $\begin{array}{l}\text { Permeability } \\
(\mu \mathrm{D})\end{array}$ & $\begin{array}{l}\text { Deviatoric stress } \\
(\mathrm{MPa})\end{array}$ & $\begin{array}{l}\text { Permeability } \\
(\mu \mathrm{D})\end{array}$ & $\begin{array}{l}\text { Deviatoric stress } \\
\text { (MPa) }\end{array}$ & $\begin{array}{l}\text { Permeability } \\
(\mu \mathrm{D})\end{array}$ \\
\hline 0 & 0.294 & 0 & 0.975 & 0 & 0.325 & 0 & 0.29528 \\
\hline 76.626 & 0.0526 & 50.972 & 0.157 & 80.305 & 0.0558 & 78.802 & 0.04848 \\
\hline 127.972 & 0.0212 & 0 & 0.628 & 0 & 0.0635 & 0 & 0.09741 \\
\hline 178.824 & 0.0216 & 76.898 & 0.0224 & 122.675 & 0.0114 & 112.961 & 0.00256 \\
\hline 216.350 & 0.00745 & 0 & 0.436 & 0 & 0.0955 & 0 & 0.0256 \\
\hline 216.860 & 0.0295 & 102.631 & 0.00342 & 163.143 & 0.00172 & 149.597 & 0.0142 \\
\hline 125.229 & 10.0339 & 0 & 0.405 & 0 & 0.121 & 0 & 0.0322 \\
\hline 115.557 & 9.808 & 132.710 & 0.00102 & 213.961 & 0.00495 & 173.593 & 0.0206 \\
\hline 109.957 & 6.891 & 0 & 0.279 & 0 & 0.122 & 0 & 0.0844 \\
\hline- & - & 163.022 & 0.0337 & 259.498 & 0.0592 & 197.287 & 0.0284 \\
\hline- & - & 0 & 0.327 & 0 & 0.155 & 0 & 0.0515 \\
\hline- & - & 175.895 & 0.0853 & 286.989 & $0.176 \sim 12.631$ & 217.185 & 0.0636 \\
\hline- & - & 0 & 0.289 & 0 & 6.524 & 0 & 0.127 \\
\hline- & - & 203.636 & 0.139 & 101.124 & 4.399 & 214.632 & 0.584 \\
\hline- & - & 0 & 0.333 & 0 & 4.069 & 0 & 0.229 \\
\hline- & - & 224.456 & 0.303 & 100.680 & 4.208 & 108.035 & 0.0857 \\
\hline- & - & 0 & 1.787 & 0 & 3.307 & - & - \\
\hline- & - & 146.504 & 0.286 & 97.334 & 3.938 & - & - \\
\hline
\end{tabular}

chamber. There are $8 \mathrm{AE}$ probes in total, which are located at 8 vertices of the three-axis outdoor wall relative to the cuboid of the rock sample. The threshold value of $\mathrm{AE}$ sampling in the experiment is set as $27 \mathrm{~dB}$.

\section{Damage defined by fractal characteristics of acoustic emission}

Figure 3 presents an evolving curve of deviatoric stress and cumulative $\mathrm{AE}$ events over the whole stressing process of rock sample. A comparison of conventional loading in Fig. 3a with progressive cyclic loading in Fig. 3b-d, the cumulative AE events display similar changing rules: (1) the number of $\mathrm{AE}$ occurrences remains fewer when deviatoric stress is low; (2) as the deviatoric stress goes up, the $\mathrm{AE}$ events rises accordingly but remains relatively low; (3) the $\mathrm{AE}$ events will rise sharply until the deviatoric stress reaches the ultimate compressive strength of the rock sample and causes damage. (4) When the rock sample gets damaged and enters the residual strength stage, the $\mathrm{AE}$ events keeps increasing. Cumulative AE events indicate for deep sandstone, almost no damage is detected on the rock sample until the deviatoric stress rises to reach the destructive strength, and the damage keeps stretching after rock sample is damaged.
In the self-similar fractal theory, for the natural discrete body of the number-radius relationship, the fractal dimension $D$ is introduced, and the relationship between the volume $M$ and the scale $r$ can be expressed as (Xie 2005)

$M(r) \sim r^{D}$

The relationship between the number $N$ of AEs in the space determined by the box dimension and the scale can be expressed as

$N(r) \sim r^{D}$

The position coordinates of the received AE signal can be calculated from the time when the AE reaches the different probes. The number of AEs in different scale spaces is obtained using the cylindrical cover method (Fig. 4). Linear fit to natural logarithm of scale and number of AEs.

From the fitting results (Fig. 5), the spatial distribution of $\mathrm{AE}$ at different scales can be expressed as

$\ln N=D \ln r+a$

explain that $\mathrm{AE}$ has good fractal characteristics in space. The fractal characteristic can be used to describe the damage on rock sample. The fractal characteristics of AE used to depict the damage in this paper include energybased AE $b$-value and spatial location-based AE correlation dimension. 


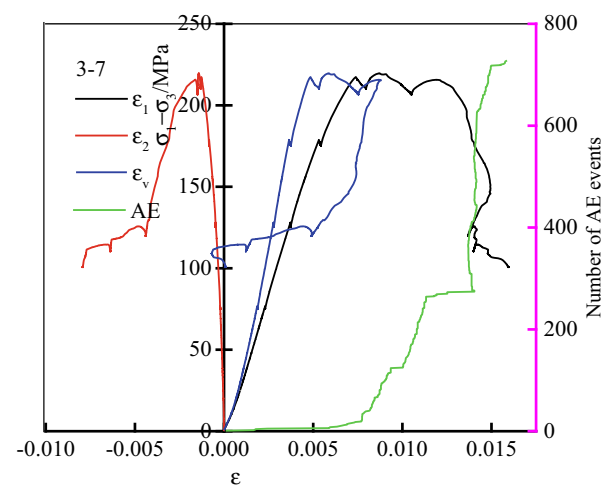

(a)

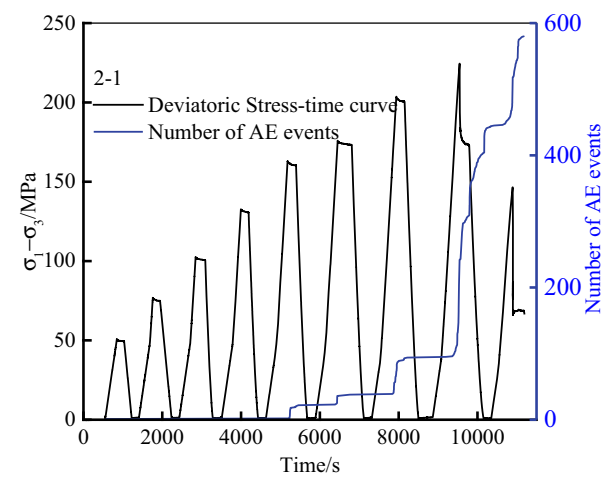

(b)

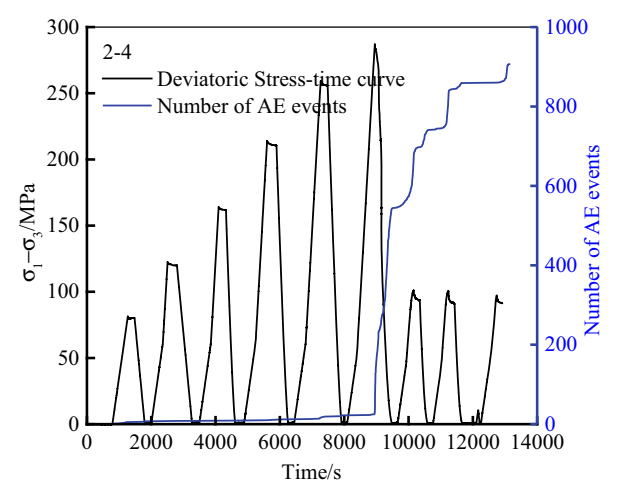

(c)

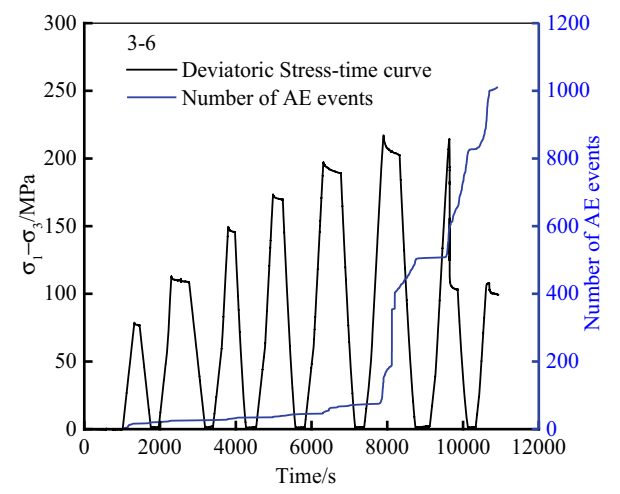

(d)
4Fig. 3 AE accumulative curve relationship with stress: a specimen 3-7, b specimen 2-1, c specimen 2-4, d specimen 3-6

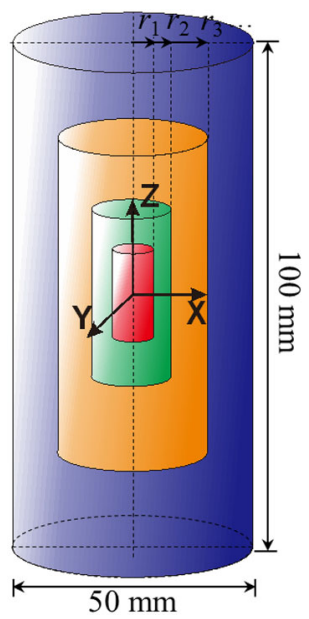

Fig. 4 Schematic diagram of cylindrical coverage of AE

\subsection{Acoustic emission b-value}

Rock damage is a process of progressive dimension-reducing and dissipation. From displaying micro-fracture to crushed failure, the rock failure features fractals. AE bvalue is the commonest fractal dimension in $\mathrm{AE}$ research, which is closely related to the absolute energy of AE event. The AE b-value can be Figured out through GutenbergRichter relation:

$\lg N=a-b \lg Q$

where $Q$ means absolute energy of AE event, $N$ means the number of events in which $\mathrm{AE}$ energy is no lower than $Q$, $a$ and $b$ are two constants. As shown in Fig. 6a, the absolute straight slope resulting from logarithmic fitting of energy $\mathrm{Q}$ and number of $\mathrm{AE}$ events $\mathrm{N}$ is the $\mathrm{AE}$ b-value. In statistical sense, b-value can represent the ratio of lowenergy AE.

\subsection{Acoustic emission correlation dimension}

$\mathrm{AE}$ correlation dimension is connected with the location information of $\mathrm{AE}$ events. When viewing the position coordinates $a_{\mathrm{i}}$ of $\mathrm{AE}$ as an element and arranging the $\mathrm{AE}$ events in time sequence, we can obtain a set of position coordinates related to $\mathrm{AE}$ events.

$\left\{\begin{array}{l}A=\left\{a_{1}, a_{2}, \ldots, a_{n}\right\} \\ a_{i}=\left\{x_{i}, y_{i}, z_{i}\right\}\end{array}\right.$ 


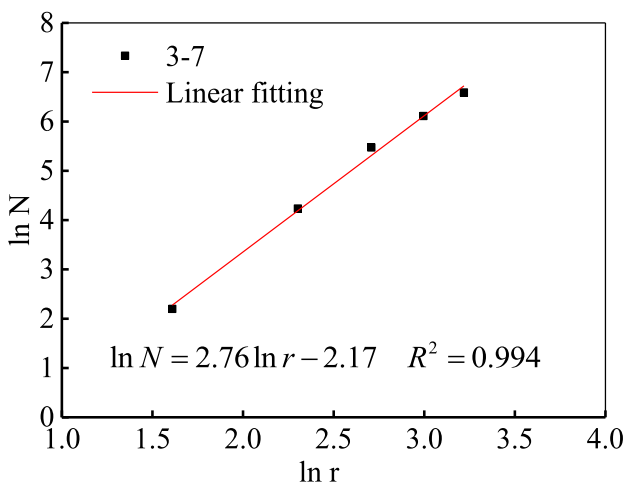

(a)

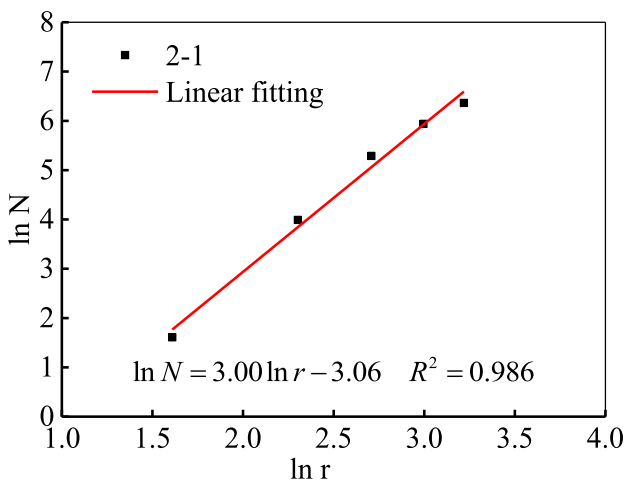

(b)

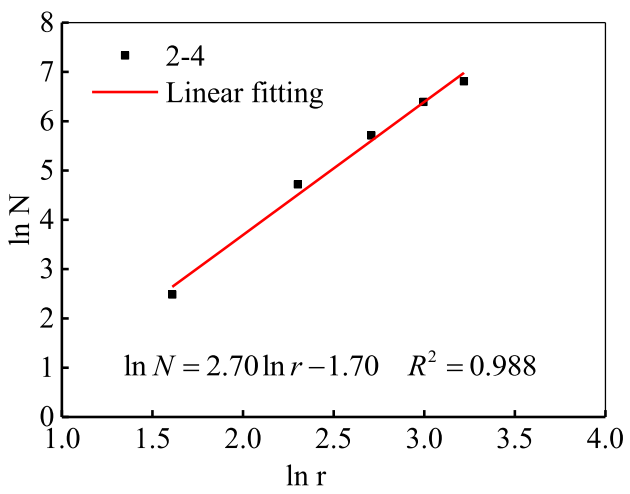

(c)

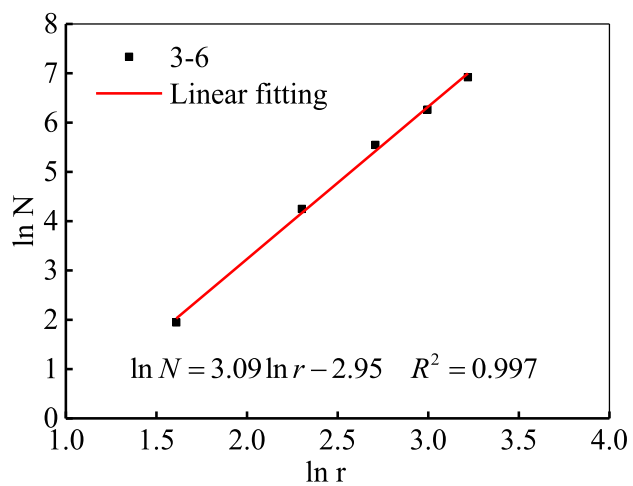

(d)
4 Fig. 5 Linear fitting of natural logarithms of different scales and number of AEs: a specimen 3-7, b specimen 2-1, c specimen 2-4, d specimen $3-6$

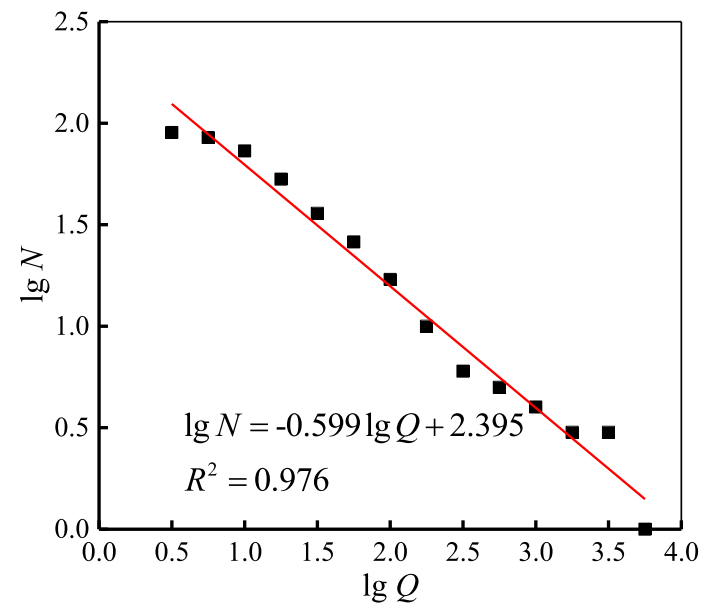

(a)

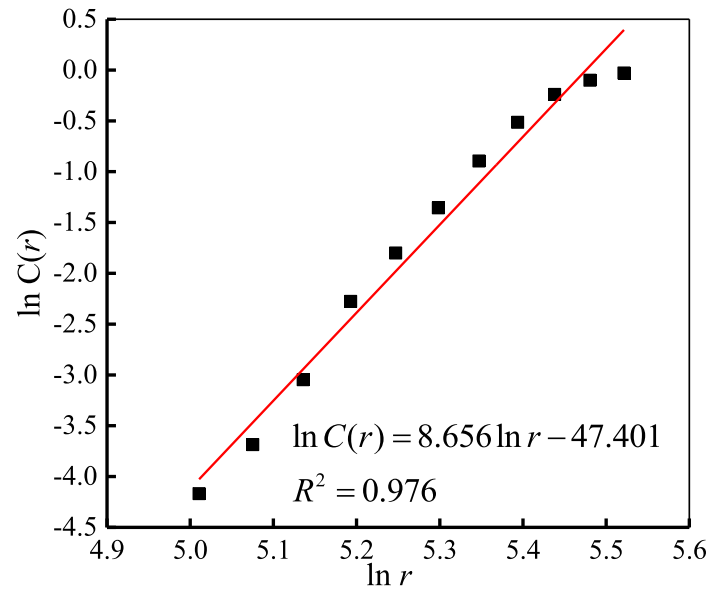

(b)

Fig. 6 Linear fitting of $\mathrm{AE} b$-value and correlation dimension: a $\mathrm{AE}$ $b$-values, b AE correlation dimension

Positive integer $m(m<n)$ can be selected to construct a $m$-dimension phase space for $\mathrm{AE}$ events in time sequence.

$$
\left\{\begin{array}{l}
A_{1}=\left\{a_{1}, a_{2}, \ldots, a_{m}\right\} \\
A_{2}=\left\{a_{2}, a_{3}, \ldots, a_{m+1}\right\} \\
\ldots \\
A_{n-m+1}=\left\{a_{n-m+1}, a_{n-m+2}, \ldots, a_{n}\right\}
\end{array}\right.
$$

For the constructed set of $m$-dimension phase space, its correlation function under given scale $r$ can be defined as: 
$C(r)=\frac{1}{N^{2}} \sum_{i=1}^{N} \sum_{j=1}^{N} H\left(r-\left\langle A_{i}-A_{j}\right\rangle\right)$

where $H(x)$ is the Heaviside function property of which can be expressed as:

$H(x)=\left\{\begin{array}{l}1, x>0 \\ 0, x \leq 0\end{array}\right.$

$\left\langle A_{i}-A_{j}\right\rangle$ represents the distance between two $m$-dimension phase spaces and its calculation formula is:

$\left\langle A_{i}-A_{j}\right\rangle=\left[\sum_{t=1}^{m}\left(A_{i, t}-A_{j, t}\right)^{2}\right]^{\frac{1}{2}}$

The meaning of correlation function lies in the ratio of $\mathrm{AE}$ events spatial distance of which is lower than scale $r$ in all the events. The reference value range for scale $r$ can be determined with Eq. (11), used to divide different scales $r$ such as $0.1 r, 0.2 r$ to $1.2 r$.

$r=\frac{1}{N^{2}} \sum_{i=1}^{N} \sum_{j=1}^{N}\left\langle A_{i}-A_{j}\right\rangle$

Correlation dimension $D$ can be determined through $\ln$ $C(r)$ and $\ln r$. As revealed in Fig. 6b, through dual-logarithmic linear fitting of correlation function and scale, the resulting slope is exactly the correlation dimension.

$D=\frac{\ln C(r)}{\ln r}$

Selection of phase space dimension $m$ and scale $r$ plays a vital role in determining correlation dimension (Kong et al. 2016; Wu et al. 2012). Figure 7 demonstrates the effect of phase space dimension $m$ on scale $r$ and correlation dimension $D$, from which it can be inferred that the reference value of scale $r$ rises with higher spatial dimension. Before rising phase space dimension reaches 26, correlation dimension keeps going up; after that, it no longer displays material change but turns to be stable on the whole. Therefore, in computing the correlation dimension $D$, the dimension of constructed phase space is supposed to be $26(m=26)$.

\subsection{Permeability and damage evolution defined by AE fractal characteristic}

Rock damage can be characterized by changes in $\mathrm{AE}$ fractal values. When $b$-value becomes lower, it means the ratio of low-energy $\mathrm{AE}$ events decreases and cumulative damage tends to be unstable; whereas when $b$-value becomes higher or fluctuates within small range, it means the rock is in relatively stable state (Zeng et al. 1995; Li et al. 2009). The change of correlation dimension can

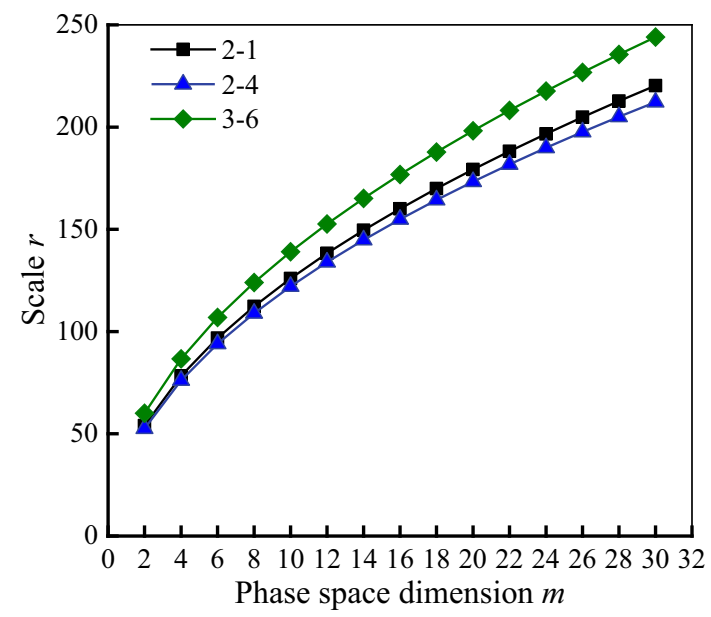

(a)

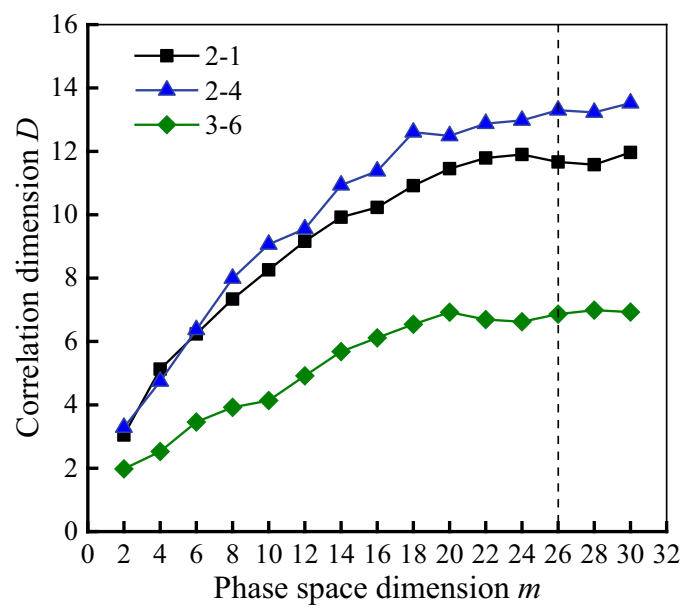

(b)

Fig. 7 The relationship between phase space dimension $m$ and scale and the correlation dimension: a scale $r, \mathbf{b}$ phase space dimension $m$

represent the faulted condition of the rock: when it keeps rising, it means inside the rock, it is relatively stable and damage is accumulating. A sudden decrease in correlation dimension indicates damage gets intensified within small area, and local failure occurs within the rock (Xu et al. 2017).

The variation of the $\mathrm{AE}$ fractal characteristic value and permeability shown in Fig. 8 can be clearly divided into three stages: before, during and after the failure of the rock. Before the failure of rock, the $\mathrm{AE}$ fractal characteristic value increases, the damage accumulation rate of the rock sample is low, the effect of rock compaction is more obvious. At this stage, the permeability first decreases with the increase of the deviatoric stress, and then rises slightly due to the accumulation of damage. When the deviatoric stress level reaches the rock strength, the rock sample damage increases sharply and the rock sample failed. At this stage, the AE fractal characteristic value showed a 


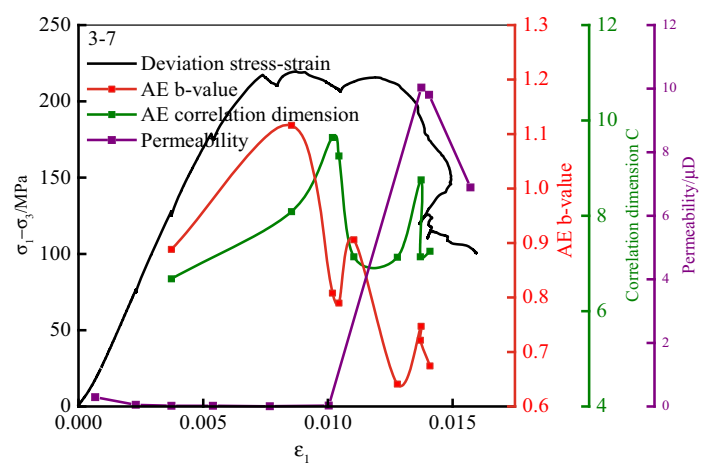

(a)

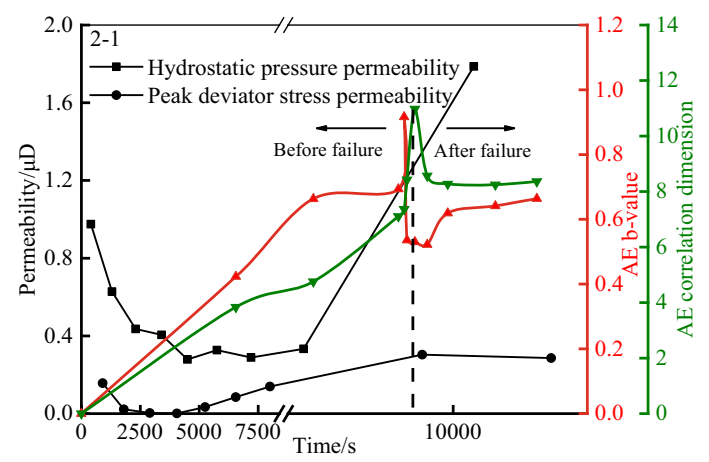

(b)

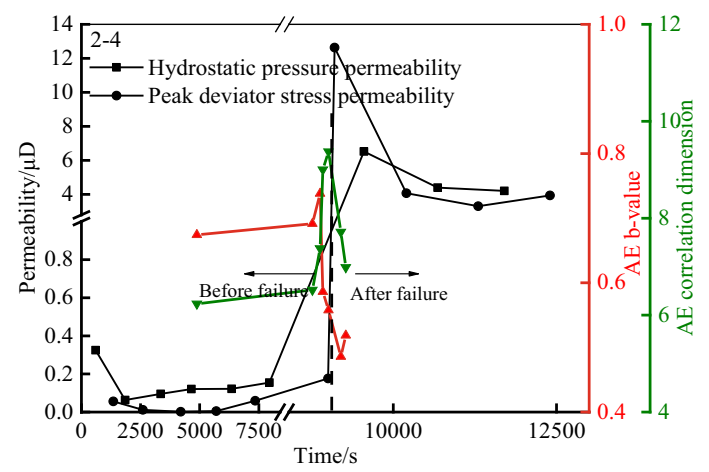

(c)

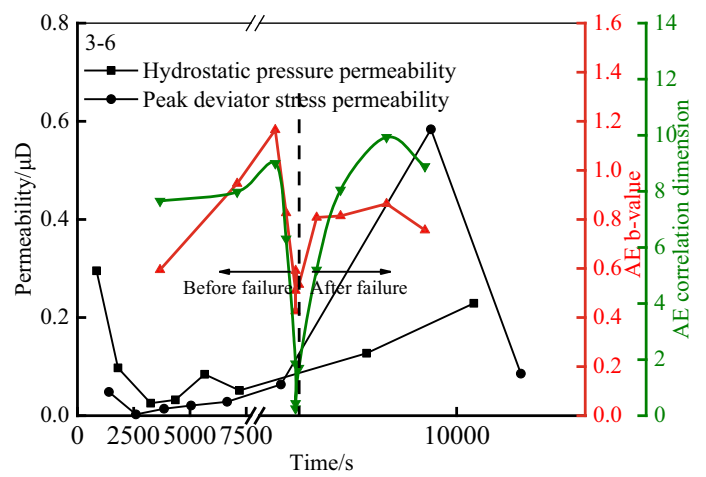

(d)

Fig. 8 The evolution of AE fractal characteristics and the permeability: a specimen $3-7$, b specimen $2-1$, c specimen $2-4$, d specimen 3-6 sharp drop, while the permeability showed a significant increase. Rocks continue to be damaged during cyclic loading after rock failure. At this stage, the AE fractal characteristics fluctuating change with the switching of the loading and unloading. Due to the continuous compaction of the deviatoric stress, the pore cracks generated during the failure are closed, and the permeability in the postdestruction stage is decreased as compared with the failure.

\section{Damage defined by the elastic modulus}

\subsection{Porosity and volume strain}

The damage of the rock and its porosity and volume strain has certain relevance. In the process of cyclic loading, the strain of the rock after one cyclic will not restore to the state before (Fig. 9). Therefore, rock volume strain is produced after each cycle. Due to the loading process rock deformation is irregular, rock porosity change can't accurate calculate by the volumetric strain, can only get the change trend of increase or decrease. In hydrostatic pressure point that rock in a low stress state, the irregular degree of rock strain is relatively low. The porosity calculated by the volumetric strain in hydrostatic pressure point is more accurate. It can be considered that at this time the variation of rock porosity and volume strain $\varepsilon_{\mathrm{v}}$ has the equal value. The porosity of the rock can be determined by

$\varphi_{i}=\varphi_{0}-\varepsilon_{v}$

where $\varphi_{\mathrm{i}}$ is the porosity under hydrostatic pressure condition; $\varphi_{0}$ is the initial porosity; $\varepsilon_{\mathrm{v}}$ is the volume strain.

\subsection{Elastic modulus and porosity}

Regard rock as a mixture of variety materials, the elastic modulus can be expressed as (Ji 2004; Yu et al. 2016)

$E^{\alpha}=\sum_{j=1}^{n} V_{j} E_{j}^{\alpha}$

where $E$ is the elastic modulus of whole rock; $E_{j}$ and $V_{j}$ is the elastic modulus and volume fraction of one material; $\alpha$ is exponent parameter. Specially $\alpha=-1$ is the Reuss model(harmonic mean) that is the lower bound of exponent parameter $\alpha . \alpha=1$ is the Voigt model(arithmetic mean) that is the upper bound of exponent parameter $\alpha$.

Porosity and elastic modulus has significant negative correlation relationship. Regard pore as a special constituent part and other materials as a whole part, obviously the volume fraction of pore is porosity. The whole rock elastic modulus can be expressed as 


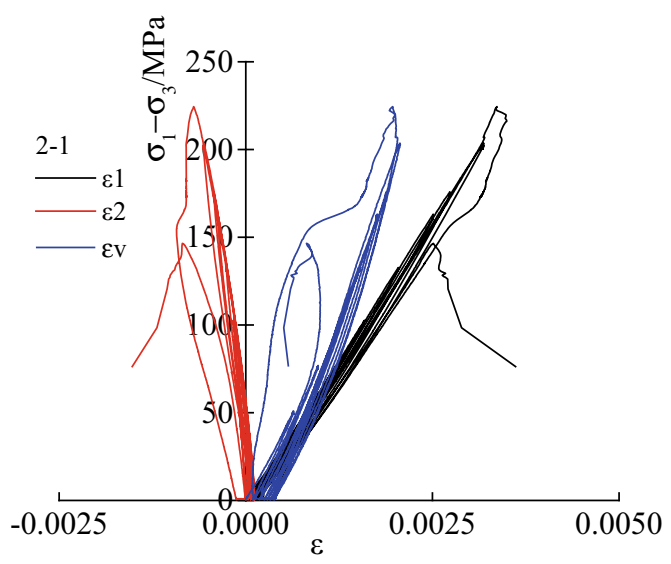

(a)

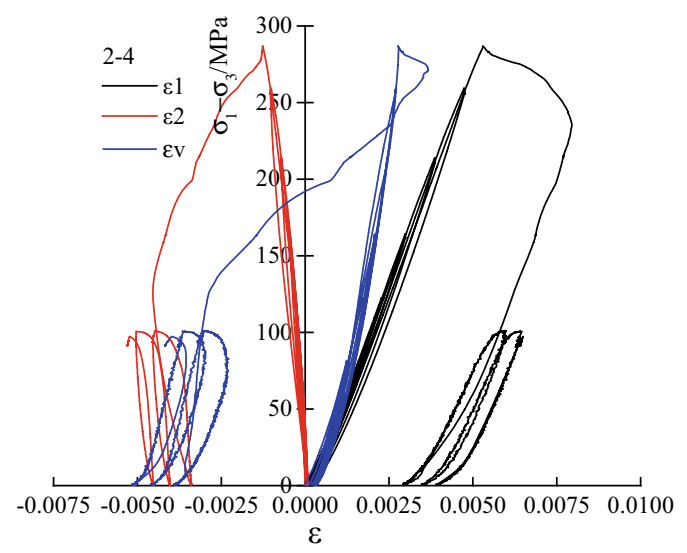

(b)

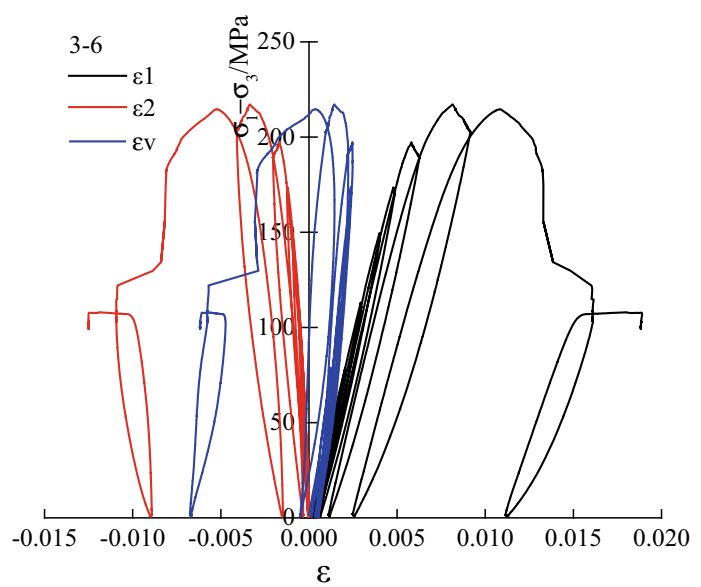

(c)

Fig. 9 Stress-strain curve: a specimen 2-1, b specimen 2-4, c specimen 3-6

$$
E=\left[(1-\varphi) E_{r}^{\alpha}+\varphi E_{\text {pore }}^{\alpha}\right]^{\frac{1}{\alpha}}, \quad E_{\text {pore }}=0
$$

where $E_{r}$ is the elastic modulus when porosity is zero; $E_{\text {pore }}$ is the elastic modulus of pore whose value is zero. It can get the result that when porosity $\varphi=0$, the elastic modulus $E=E_{r}$ and when $\varphi=1, E=0$. It has practical meaning when $\alpha>0$. Introduce rock initial porosity $\varphi_{0}$ and elastic modulus $E_{0}$, Eq. (15) can be simplified as

$\frac{E_{0}}{E_{r}}=\left(1-\varphi_{0}\right)^{\frac{1}{\alpha}}$

Then the relationship between rock porosity $\varphi_{i}$ and elastic modulus $E_{i}$ after the $i$ th cycle can be expressed as

$\frac{E_{i}}{E_{0}}=\left(\frac{1-\varphi_{i}}{1-\varphi_{0}}\right)^{\frac{1}{\alpha}}$

where $E_{i}$ is the elastic modulus of the i-th cycle loading phase; $E_{O}$ is the initial elastic modulus of the rock sample; $\varphi_{i}$ is the porosity of the rock sample before the ith cycle loading; $\varphi_{O}$ is the initial porosity of the rock sample; $\alpha$ is exponent parameter.

The comparison of experimental values and the calculated value obtained by the Eq. (17) is shown in Fig. 10. The results show that the experimental value is close to the calculated value. Equation (17) can express the relationship between the elastic modulus and the porosity.

\subsection{Compression parameter $C$ to characterize damage}

In the process of cyclic loading, rock is simultaneously subjected to stress compaction and fracturing. The compaction causes the rock structure to become tight and the fracturing cause damage. For deep roof sandstone, the elastic modulus changes with cyclic stress. When the stress is small, the rock mainly exhibits compaction, and the elastic modulus will increase slightly. When the stress is large, the rock accumulates damage due to fracturing and exhibits yielding tendency, the elastic modulus will be reduced. When the stress reaches the compressive strength of the rock, the rock will be destroyed and the elastic

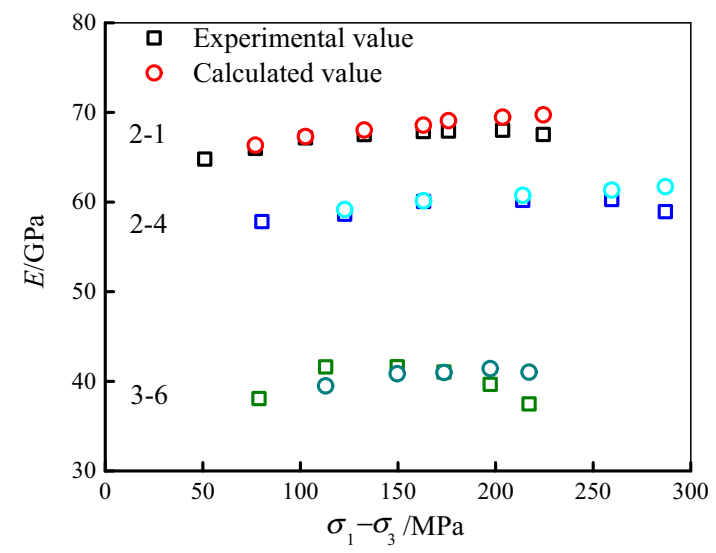

Fig. 10 Elastic modulus experimental values and calculated values 
modulus will be greatly reduced. Introduce compression parameter $C$ to define the degree of damage to the rock.

$C=1-\frac{E_{\mathrm{i}}}{E_{0}}=1-\left(\frac{1-\varphi_{i}}{1-\varphi_{0}}\right)^{\frac{1}{\alpha}}$

where $E_{\mathrm{i}}$ is the elastic modulus of the rock during a certain cyclic loading phase; $E_{0}$ is the initial elastic modulus of the rock. For deep rocks, the lower stress conditions result in a small increase in the elastic modulus of the rock due to compaction. When the elastic modulus of rock increases, a negative value of $C$ indicates the compaction of rock sample. And when the elastic modulus begins to decrease, the increasing value of $C$ indicates fracturing and damage. When the value of $C$ is above zero, indicates that the rock volume is expanded and the damage will be particularly large. The compression parameter $C$ can be calculated for the change of the elastic modulus is known, and its variation law is shown in Fig. 11. Taking the inflection point as the boundary it can be divided into two stages, compression and fracturing.

\subsection{The relationship between compression parameter $C$ and permeability}

Before rock is destroyed the infiltration forms of rock in the process of stress-strain mainly include porous medium penetration and fracture medium penetration (Bai et al. 2010; Valliappan and Khalili-Naghadeh 1990). When the rock damage is small, it mainly manifests as the permeability of the porous medium. When the rock damage is intensified, both occur simultaneously when the internal fracture occurs. Before the rock failure, some scholars have established a model of the relationship between permeability and porosity (Cai et al. 2014; Palmer and Mansoori 1998; Pan and Connell 2012; Reiss 1980; Shi and Durucan 2004; Zhou et al. 2018):

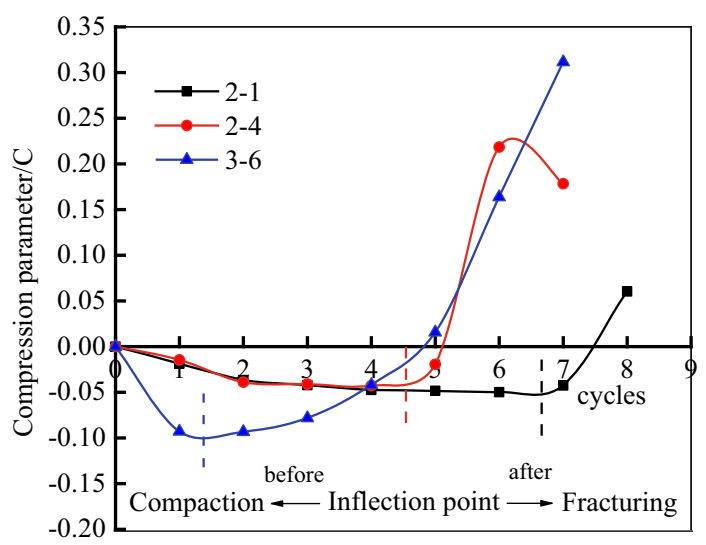

Fig. 11 The evolution of the compression parameter $C$
$\frac{K}{K_{0}}=d\left(\frac{\varphi}{\varphi_{0}}\right)^{\beta}$

where $K$ is the permeability of measuring point, $K_{0}$ is the initial permeability, $d$ is constant coefficient, $\varphi$ is porosity of measuring point, $\varphi_{0}$ is initial porosity.

For this experiment, the ratio of the permeability to the initial permeability per cycle to the hydrostatic pressure

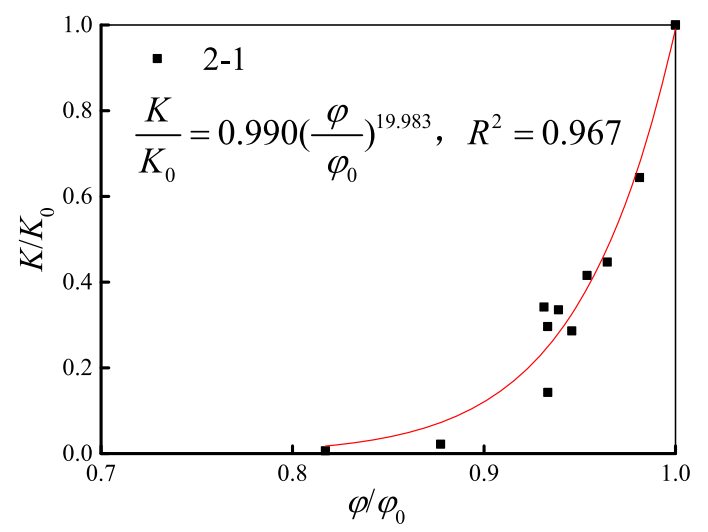

(a)

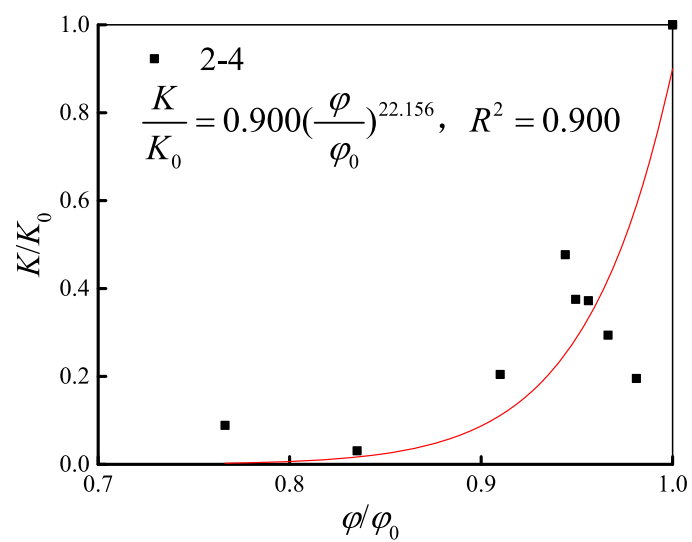

(b)

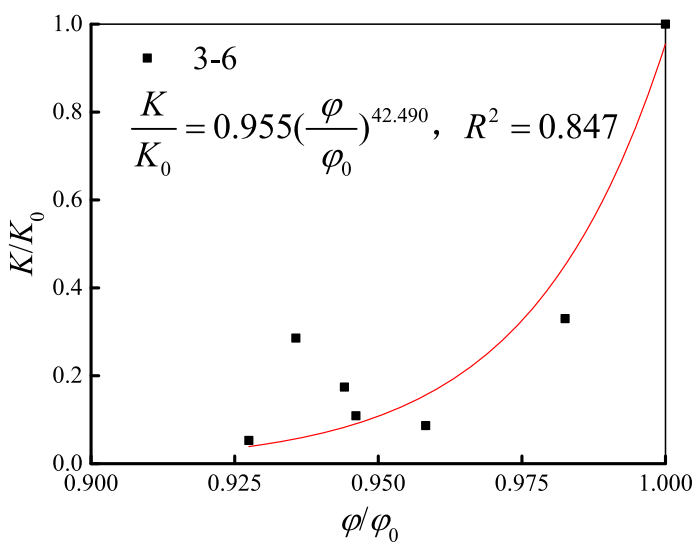

(c)

Fig. 12 Fitting relationship of permeability and porosity: a specimen $2-1$, b specimen $2-4$, c specimen $3-6$ 
point and the ratio of the porosity to the initial porosity have a fitting relationship as shown in Fig. 12. The results show that for the deep sandstone, there is a power law function relationship between the porosity and the permeability before rock failure.

By rewriting the constant term in the formula, Eq. (18) can be rewrote as

$$
\left\{\begin{array}{l}
C=1-d_{1}\left(1-\varphi_{i}\right)^{d_{2}} \\
d_{1}=\left(1-\varphi_{0}\right)^{-\frac{1}{\alpha}} \\
d_{2}=\frac{1}{\alpha}
\end{array}\right.
$$

and Eq. (19) as

$$
\left\{\begin{array}{l}
K=d_{3} \varphi_{i}^{d_{4}} \\
d_{3}=a K_{0} \varphi_{0}^{-\beta} \\
d_{4}=\beta
\end{array}\right.
$$

where $d_{1,2,3,4}>0$. Solving the compression parameter to porosity and the permeability to porosity derivative function can obtain that both the first-order and second-order derivative functions are greater than zero in the range of $0<\varphi<1$. It shows that the compression parameters and permeability are positively correlated via porosity. Combining Eqs. (13), (20), (21) it can be seen that both the permeability and the compression parameters have a power-law relationship with the porosity and the monotonicity of the function is consistent. It can be concluded that the permeability and compression parameters should have the same evolution law. The variation law of the compression parameter $C$ and the permeability $K$ under hydrostatic pressure under the condition of cyclic loading is shown in Fig. 13. The experimental results show that the compression parameters and the permeability change with volume strain are consistent. It is proved that the use of compression parameters to indicate rock damage and permeability evolution is feasible.

Further, the functional relationship between compression parameters and permeability can be expressed as

$$
\begin{aligned}
K & =d_{3}\left[1-\left(\frac{1-C}{d_{1}}\right)^{\frac{1}{d_{2}}}\right]^{d_{4}} \\
& =d K_{0}\left[\frac{1-\left(1-\varphi_{0}\right)(1-C)^{\alpha}}{\varphi_{0}}\right]^{\beta}
\end{aligned}
$$

where the parameters in Eq. (22) is shown in Table 3.

Solving the first derivative of the permeability versus the compression parameter can get Eq. (23):

$$
K^{\prime}=d K_{0} \alpha \beta \frac{1-\varphi_{0}}{\varphi_{0}}(1-C)^{\alpha-1}\left[\frac{1-\left(1-\varphi_{0}\right)(1-C)^{\alpha}}{\varphi_{0}}\right]^{\beta-1}
$$

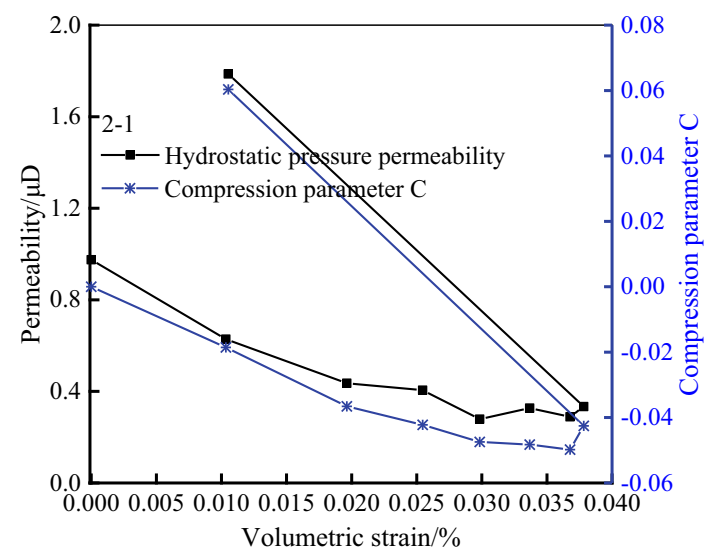

(a)

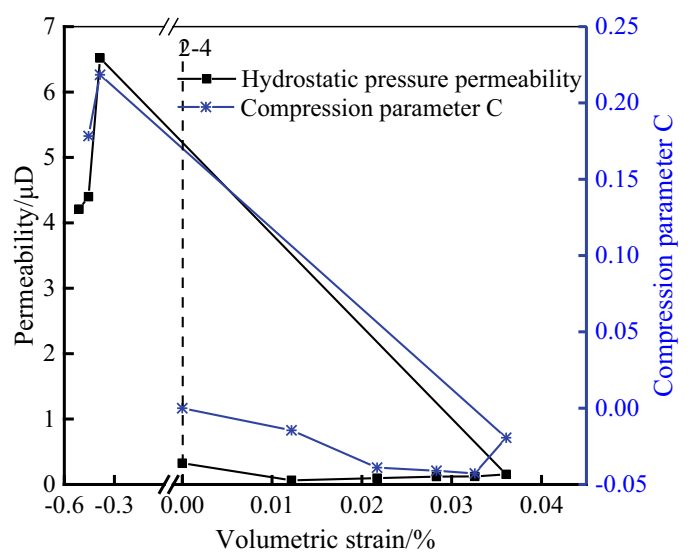

(b)

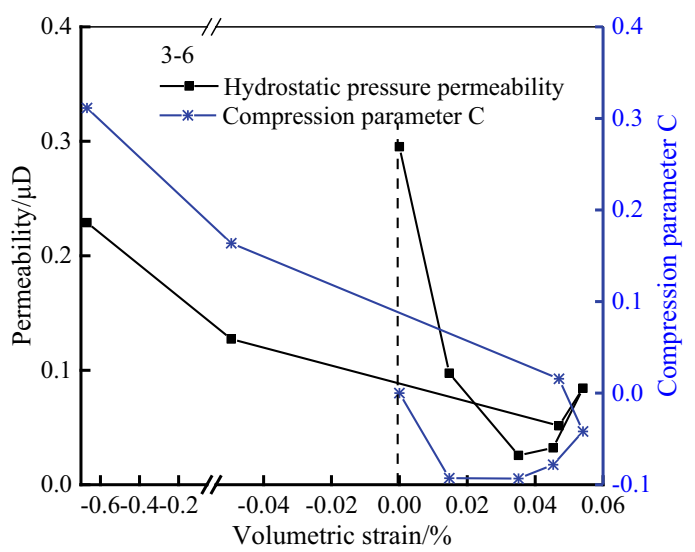

(c)

Fig. 13 Evolution law of permeability and compression parameters: a specimen $2-1$, b specimen $2-4$, c specimen $3-6$

Since the parameters are all known be positive, the derivative function is positive, indicating that the permeability is positively correlated with the compression parameter.

The experimental values of the permeability and the compression parameter are compared with the calculated 
Table 3 Parameters of rock sample in Eq. (22)

\begin{tabular}{llllll}
\hline Specimen & $d$ & $K_{0}(\mathrm{Md})$ & $\varphi_{0}(\%)$ & $\alpha / 10^{-3}$ & $\beta$ \\
\hline $2-1$ & 0.990 & 0.975 & 0.551 & 5.294 & 19.983 \\
$2-4$ & 0.900 & 0.325 & 0.644 & 5.637 & 22.156 \\
$3-6$ & 0.955 & 0.295 & 0.841 & 6.368 & 42.490 \\
\hline
\end{tabular}

values based on Eq. (22) and shown in Fig. 14. The compression parameter is positively correlated with the permeability, and the experimental values are in good agreement with the calculated values when $C<0$. When the compression parameter is greater than zero, the rock entering the stage of yield failure, the relationship between porosity and permeability no longer satisfies Eq. (19). The experimental value and the calculated value begin to produce a large deviation. The results show that Eq. (22) can describe the evolution law of permeability and damage when the rock compression parameter is less than zero. When the volumetric strain of the rock is expanded, it can only explain the change trend of permeability and damage.

\section{Conclusions}

In this paper, the cyclic loading permeability $\mathrm{AE}$ experiment of the roof sandstone in the deep coal seam working face is carried out, and the following main conclusions are obtained:

(1) The permeability of deep sandstone has obvious phase characteristics under different stress conditions. Reduce at low stress levels and shows a small increase when the stress gradually approaches the rock strength. When the stress reaches the rock strength, it shows greatly increased and a small reduction after failure.

(2) The AE generated during rock loading and unloading has good fractal characteristics. The AE $b$-value and the $\mathrm{AE}$ correlation dimension $D$ can reflect the damage of the rock under stress through its change. When the AE $b$-value and the AE correlation value rise, it indicates stability, and greatly reduced characterize the damage.

(3) The increase and decrease of rock elastic modulus during cyclic loading can reflect its damage state. When the stress is low, the elastic modulus of the rock increases slightly, indicating that the rock is compacted. When the stress is large, the elastic modulus begins to decrease, indicating that the rock is damaged. When the stress reaches the compressive strength, the elastic modulus decreases drastically,

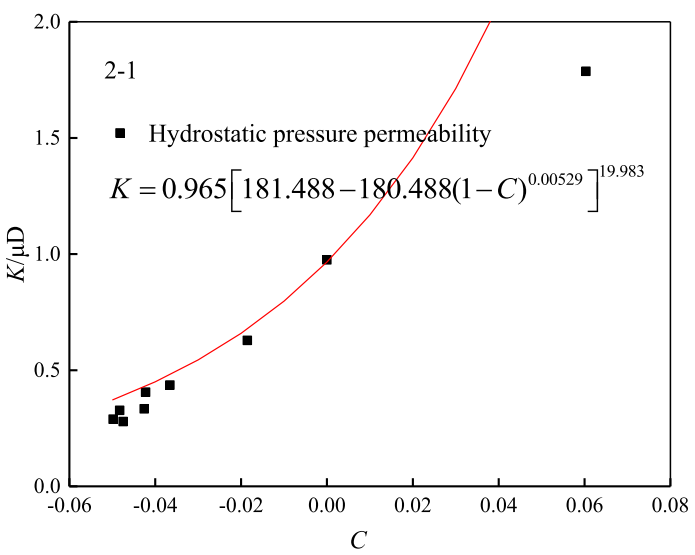

(a)

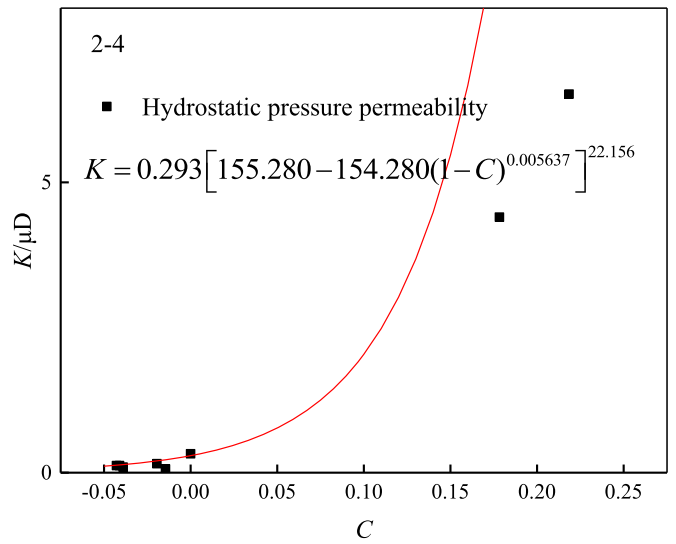

(b)

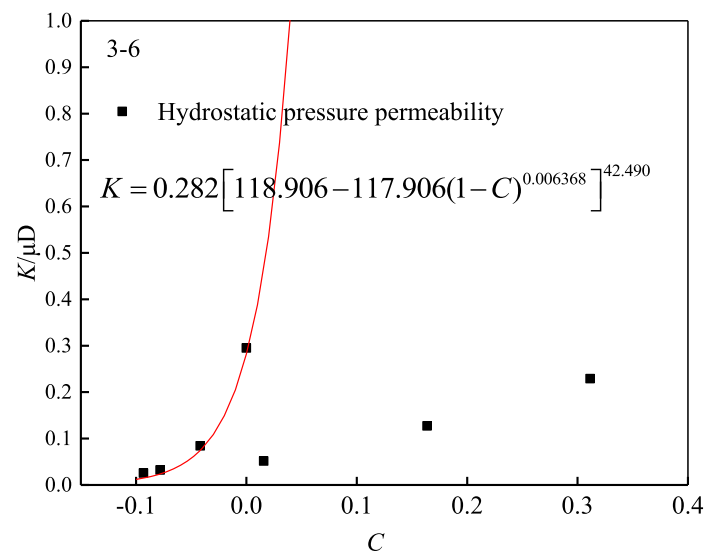

(c)

Fig. 14 The relationship between permeability $K$ and compression parameter $C$ : a specimen $2-1$, b specimen $2-4$, c specimen 3-6

indicating that the rock sample is destroyed. The damage of the rock can be quantified by the compression parameter $C$. Before the compression parameter reach the inflection point, it indicates compaction and the damage is not obvious. After the inflection point compression parameter is increasing to positive, it means fracturing and damage. 
(4) Both permeability and compression parameter show a power law function relationship with porosity and uniform monotonicity. The permeability and compression parameter under hydrostatic pressure have the same evolution law with volumetric strain during the cyclic loading process.

(5) The relationship between permeability and compression parameter can better represent the evolution law of permeability and damage when the compression parameter is less than zero.

Acknowledgements The present work is supported by the National Natural Science Foundation of China (51904309, 51674266) and the Yueqi Outstanding Scholar Program of CUMTB and the State Key Research Development Program of China (2016YFC0600704). The financial supports are gratefully acknowledged.

Open Access This article is distributed under the terms of the Creative Commons Attribution 4.0 International License (http://crea tivecommons.org/licenses/by/4.0/), which permits unrestricted use, distribution, and reproduction in any medium, provided you give appropriate credit to the original author(s) and the source, provide a link to the Creative Commons license, and indicate if changes were made.

\section{References}

Bai M, Ma Q, Roegiers JC (2010) Dual-porosity behaviour of naturally fractured reservoirs. Int $\mathrm{J}$ Numer Anal Methods Geomech 18(6):359-376. https://doi.org/10.1002/nag. 1610180602

Brace WF, Walsh JB, Frangos WT (1968) Permeability of granite under high pressure. J Geophys Res 73(6):2225-2236

Cai MF, He MC, Liu DY (2002) Rock mechanics and engineering. Science Press, Beijing (in Chinese)

Cai YD, Liu DM, Mathews JP, Pan ZJ, Elsworth D, Yao YB, Li JQ, Guo XQ (2014) Permeability evolution in fractured coalcombining triaxial confinement with X-ray computed tomography, acoustic emission and ultrasonic techniques. Int J Coal Geol 122:91-104. https://doi.org/10.1016/j.coal.2013.12.012

Eberhardt E, Stead D, Stimpson B, Read RS (1998) Identifying crack initiation and propagation thresholds in brittle rock. Can Geotech J 35(2):222-233. https://doi.org/10.1139/cgj-35-2-222

Elliott GM, Brown ET (1986) Further development of a plasticity approach to yield in porous rock. Int $\mathrm{J}$ Rock Mech Min Sci Geomech Abstr 23(2):151-156. https://doi.org/10.1016/01489062(86)90341-4 (Pergamon)

Escoffier S, Homand F, Giraud A, Hoteit N, Su K (2005) Under stress permeability determination of the Meuse/Haute-Marne mudstone. Eng Geol 81(3):329-340. https://doi.org/10.1016/j. enggeo.2005.06.020

Fang Z, Harrison JP (2002) Application of a local degradation model to the analysis of brittle fracture of laboratory scale rock specimens under triaxial conditions. Int $\mathrm{J}$ Rock Mech Min Sci 39(4):459-476. https://doi.org/10.1016/S1365-1609(02)00036-9

Ji SC (2004) A generalized mixture rule for estimating the viscosity of solid-liquid suspensions and mechanical properties of polyphase rocks and composite materials. J Geophys Res 109(B10):B10207. https://doi.org/10.1029/2004jb003124

Kong X, Wang E, Hu S, Shen R, Li X, Zhan T (2016) Fractal characteristics and acoustic emission of coal containing methane in triaxial compression failure. J Appl Geophys 124:139-147. https://doi.org/10.1016/j.jappgeo.2015.11.018

Lajtai EZ, Lajtai VN (1974) The evolution of brittle fracture in rocks. J Geol Soc 130(1):1-16. https://doi.org/10.1144/gsjgs.130.1. 0001

Li HG, Li HM (2017) Mechanical properties and acoustic emission characteristics of thick hard roof sandstone in Shendong coal field. Int J Coal Sci Technol 4(2):147-158. https://doi.org/10. 1007/s40789-017-0163-4

Li XC, Takahashi M, Wu ZS, Koide H (2001) Transient pulse technique and its application to conventional triaxial compressive tests. Chin J Rock Mech Eng 20(z1):1725-1733. https://doi. org/10.3321/j.issn:1000-6915.2001.z1.025 (in Chinese)

Li YH, Liu JP, Zhao XD, Yang YJ (2009) Study on $b$-value and fractal dimension of acoustic emission during rock failure process. Rock Soil Mech 30(9):2559-2563. https://doi.org/10. 1016/S1874-8651(10)60073-7 (in Chinese)

Martin CD, Chandler NA (1994) The progressive fracture of Lac du Bonnet granite. Int J Rock Mech Min Sci Geomech Abstr 31(6):643-659. https://doi.org/10.1016/0148-9062(94)90005-1 (Pergamon)

Palmer I, Mansoori J (1998) How permeability depends on stress and pore pressure in coalbeds: a new model. SPE Reserv Eval Eng 1(6):539-544. https://doi.org/10.2118/52607-pa

Pan ZJ, Connell LD (2012) Modelling permeability for coal reservoirs: a review of analytical models and testing data. Int J Coal Geol 92:1-44. https://doi.org/10.1016/j.coal.2011.12.009

Reiss LH (1980) The reservoir engineering aspects of fractured formations, Editions Technip.

Shi JQ, Durucan S (2004) Drawdown induced changes in permeability of coalbed: a new interpretation of the reservoir response to primary recovery. Transp Porous Media 56(1):1-16. https://doi. org/10.1023/B:TIPM.0000018398.19928.5a

Sun JC, Yang ZM, Guo HK, Xiao QH, He MX, Xu X (2013) Comparative study of tight reservoir permeability using steadystate and unsteady-state methods. Rock Soil Mech 34(4):1009-1016 (in Chinese)

Valliappan S, Khalili-Naghadeh N (1990) Flow through fissured porous media with deformable matrix. Int $\mathrm{J}$ Numer Methods Eng 29(5):1079-1094. https://doi.org/10.1002/nme.1620290512

Wang HL, Xu WY, Zuo J, Shao JF, Jia CJ (2015a) Evolution law of the permeability and porosity for low-permeability rock based on gas permeability test. J Hydraul Eng 46(2):208-216. https://doi. org/10.13243/j.cnki.slxb.2015.02.010 (in Chinese)

Wang W, Xu WY, Wang RB, Cao YJ, Wang HL, Feng SR (2015b) Permeability of dense rock under triaxial compression. Chin J Rock Mech Eng 34(1):40-47. https://doi.org/10.13722/j.cnki. jrme.2015.01.005 (in Chinese)

Wu XZ, Liu XX, Liang ZZ, You X, Yu M (2012) Experimental study of fractal dimension of $\mathrm{AE}$ serials of different rocks under uniaxial compression. Rock Soil Mech 3(12):3561-3569. https:// doi.org/10.1161/01.STR.3.2.181 (in Chinese)

Xie HP (2005) Introduction to Fractal Rock Mechanics. China Science Publishing, Beijing (in Chinese)

Xu J, Jiang JD, Zuo LL, Gao YF (2017) Acoustic emission monitoring and failure precursors of sandstone samples under various loading and unloading paths. Shock Vib 6:1-11. https:// doi.org/10.1155/2017/9760940

Yu CB, Ji SC, Li Q (2016) Effects of porosity on seismic velocities, elastic moduli and Poisson's ratios of solid materials and rocks. J Rock Mech Geotech Eng 8(1):35-49. https://doi.org/10.1016/j. jrmge.2015.07.004

Zeng ZW, Ma J, Liu LQ, Liu TC (1995) AE $b$-value dynamic features during rockmass fracturing and their significances. Seismol Geol 17(1):7-11. https://doi.org/10.1088/0256-307X/12/7/010 (in Chinese) 
Zhang QB, Zhao J (2013) A review of dynamic experimental techniques and mechanical behavior of rock materials. Rock Mech Rock Eng 47(4):1411-1478. https://doi.org/10.1007/ s00603-013-0463-y

Zhang M, Takahashi M, Morin RH, Esaki T (2000a) Evaluation and application of the transient-pulse technique for determining the hydraulic properties of low-permeability rocks-part 1 : theoretical evaluation. Geotech Test J 23(1):83-90. https://doi.org/10. 1520/GTJ11126J

Zhang M, Takahashi M, Morin RH, Esaki T (2000b) Evaluation and application of the transient-pulse technique for determining the hydraulic properties of low-permeability rocks-part 2: experimental application. Geotech Test J 23(1):91-99. https://doi.org/ 10.1520/GTJ11126J

Zhang HM, Lei LN, Yang GS (2015) Characteristic and representative model of rock damage process under constant confining stress. J China Univ Min Technol 44(1):59-63. https://doi.org/ 10.13247/j.cnki.jcumt.000279 (in Chinese)
Zhou HW, Xie HP, Zuo JP (2005) Developments in researches on mechanical behaviors of rocks under the condition of high groud pressure in the depth. Adv Mech 35(1):91-99. https://doi.org/10. 3321/j.issn:1000-0992.2005.01.009 (in Chinese)

Zhou HW, Xie HP, Zuo JP, Du SH, Man K, Yan CY (2010) Experimental study of the effect of depth on mechanical parameters of rock. Chin Sci Bull 55(34):3276. https://doi.org/ 10.1360/972010-786 (in Chinese)

Zhou HW, Zhong JC, Ren WG, Wang XY, Yi HY (2018) Characterization of pore-fracture networks and their evolution at various measurement scales in coal samples using X-ray $\mu \mathrm{CT}$ and a fractal method. Int J Coal Geol 189:35-49. https://doi.org/ 10.1016/j.coal.2018.02.007

Zhou HW, Wang ZH, Wang CS, Liu JF (2019) On acoustic emission and post-peak energy evolution in Beishan granite under cyclic Loading. Rock Mech Rock Eng 52(1):283-288. https://doi.org/ 10.1007/s00603-018-1614-y 